Document downloaded from:

http://hdl.handle.net/10251/120697

This paper must be cited as:

Santos-Sousa, MR.; Lora-García, J.; López Pérez, MF. (2018). Modelling approach to an ultrafiltration process for the removal of dissolved and colloidal substances from treated wastewater for reuse in recycled paper manufacturing. Journal of Water Process Engineering. 21:96-106. https://doi.org/10.1016/j.jwpe.2017.11.017

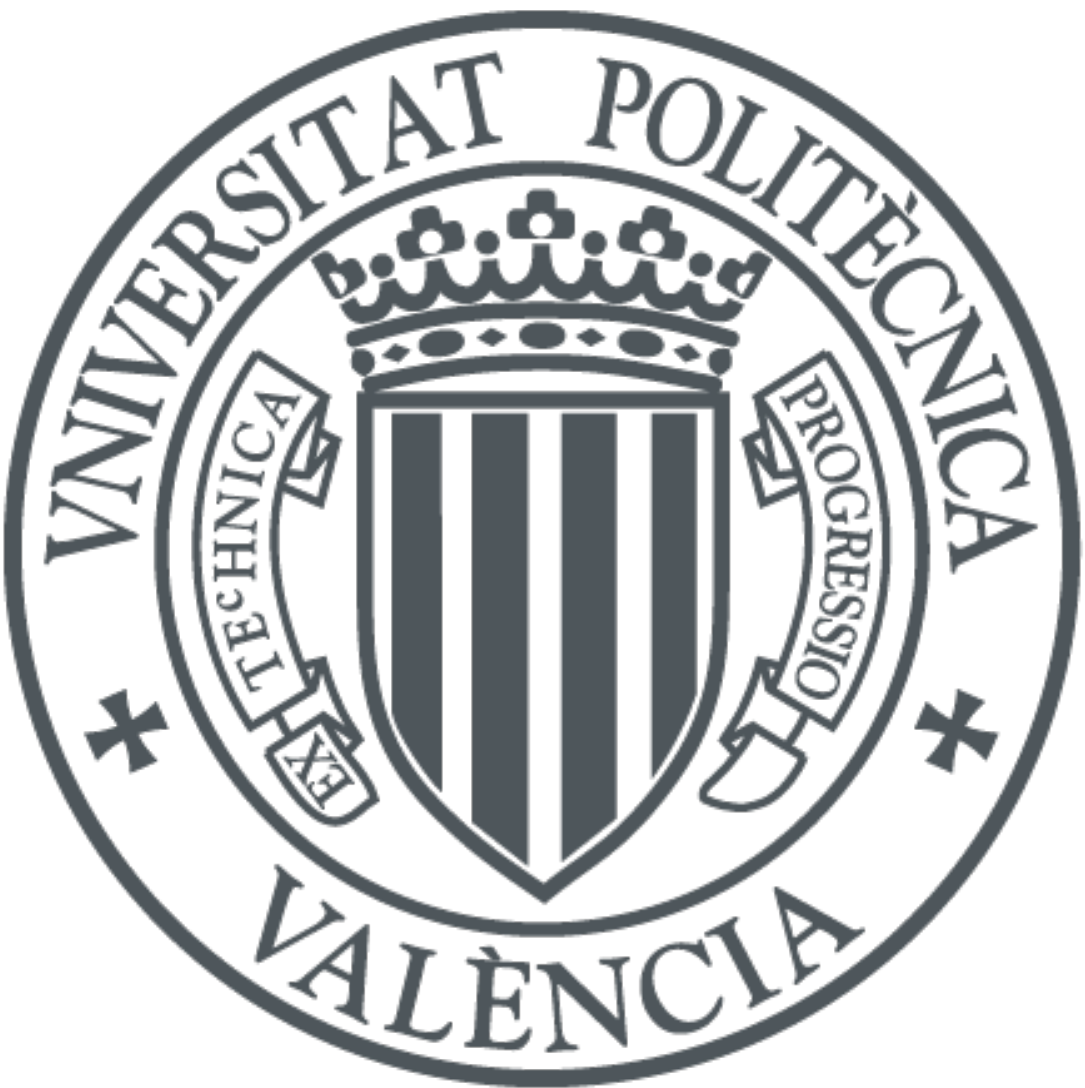

The final publication is available at

https://doi.org/10.1016/j.jwpe.2017.11.017

Copyright Elsevier

Additional Information 


\section{Modelling approach to an ultrafiltration process for the removal of dissolved and colloidal substances from treated wastewater for reuse in recycled paper manufacturing}

Mayko Rannany S. Sousa*; Jaime Lora-Garcia ; Maria-Fernanda López-Pérez

Instituto de Seguridad Industrial, Radiofísica y Medioambiental (ISIRYM) Universitat Politècnica de València (UPV). Plaza Ferrándiz y Carbonell, s/n 03801 Alcoy (Spain).

*maysanso@doctor.upv.es

In this work, ultrafiltration (UF) is used to remove dissolved and colloidal substances (DCS) from a secondary clarifier effluent from a wastewater treatment plant (WWTP) in a papermaking factory. The approach has been to examine and model the decline in permeate flux resulting from membrane fouling. Effluent from a WWTP at a papermaking factory, previously filtered, was used as feed. UF experiments were carried out in a laboratory-scale plant using a $10 \mathrm{kDa}$ polyethersulfone (PES) UF membrane in a flat sheet module with an active area of $154.8 \mathrm{~cm}^{2}$. The transmembrane pressure (TMP) (1-3 bar) and crossflow rate (1.5-4.5 $\mathrm{L} / \mathrm{min})$ were varied during the experiments, at constant temperature $\left(22 \pm 0.5^{\circ} \mathrm{C}\right)$. Experimental results from UF tests were expressed in terms of permeate flux (Jp) as a function of time to check modified Hermia's models adapted to crossflow filtration. The parameters of these models were theoretically estimated. The predicted results were compared with experimental data with a high goodness of fit. The results showed that the phenomenon controlling fouling, under most of the conditions tested, was intermediate blocking $\left(\mathrm{R}^{2}>0.96\right)$. Measurements of particle size distribution and zeta potential near the isoelectric point, showed a substantial reduction in colloidal compounds. Additionally, given that COD was removed down to 110 $\mathrm{mg} / \mathrm{L}$, it could be said that UF is suitable for producing water that can be reused in different papermaking processes.

Keywords: Ultrafiltration, modelling, treated wastewater, colloidal and dissolved substances (DCS), paper mill.

\section{Introduction}

The pulp and paper $(\mathrm{P} \& \mathrm{P})$ industry represents one of the most important industries of the European economic sector. According to data from 2010 the sector had a total turnover of 76.4 billion euros, employing about 225,000 people directly [1]. According to Key Statistics 2014- 
CEPI, Europe is the second largest producer of paper and paperboard with 22.7\% (91.39 million tons) of world production (Asia 45.3\% and North America 21.1\%), and the third largest consumer with $18.9 \%$ (76.28 million tons), behind Asia the leader with 46.6\%, and North America with $19.2 \%$. These industries commonly produce considerable amounts of wastewater and face challenges to comply with stringent environmental regulations. In this regard, the European Commission has described the best available techniques (BAT) to be adopted by P\&P mills [2].

Wastewater from the paper industry contains a high biodegradable organic matter loading and its volume is high in relation to production. Paper mill wastewater carries significant quantities of fibre (losses with effluent $0.5-5 \%$ of total fibre amount), filler, fines and other wet-end additives that contribute to total suspended solids (TSS), chemical oxygen demand (COD) and biological oxygen demand (BOD). TSS varies significantly from mill to mill, based on the type of internal clarification equipment used, equipment arrangement and design philosophy. COD depends on the amount of suspended solids such as fibre, fines, and other chemically oxidisable wet-end additives such as starch. BOD is high due to the presence of large amounts of oxidisable materials, such as fibre, fines, starch, wet and dry strength resins, drainage aids, dyes, sizing materials and other dissolved organics [3]. Furthermore, the volume, properties and characteristics of P\&P generated wastewater depend on several factors such as the type of paper production (packaging paper, corrugated cardboard, light-weight coated paper, printing and writing paper), the raw materials used in the manufacturing process, which can be from virgin fibre or recovered fibres (RCFs), the production process employed, applied technologies, additive chemicals and the amount of water consumed. It is important to mention that the wastewater generated in a RCF mill is quite small compared to that from a virgin $\mathrm{P} \& \mathrm{P}$ production process $[4,5]$.

In fact, P\&P industry recovery of waste papers such as mixed office waste, old cardboard, old newsprint and old corrugated containers has increased over recent decades, due of a number of favourable factors such as raw material economy, natural resources saving, reductions in solid waste and effluent [6]. However, when recycled paper is used (RCF mills) the effluent is characterised by a variable loading of fibres, pulping additive chemicals and other impurities such as short fines and fillers, which are generally not very soluble. In addition, the concentration of dissolved organic pollutants is particularly high and directly related to the origin of the waste papers [7, 8]. Zwain et al. [9] studied some physical-chemical characteristics of recycled paper wastewater as presented in Table 1. 
Paper mills have their own wastewater treatment plants, but this treatment does not achieve the pollutant loadings permissible under current regulations. As a result, the wastewater must be sent to municipal WWTPs, causing problems in designed operational conditions. Most pulp and paper mills treat their effluent by using an activated sludge process. However, this biologically treated effluent still contains significant amounts of colour compounds, microorganisms, recalcitrant organics and a minor amount of biodegradable organics as well as suspended solids. Therefore, the biological treatment does not significantly reduce the inorganic content of the effluent. As a result, the water is still not sufficiently clean after this process for reuse in the production of most paper. Pulp and paper mill effluents can be reused for the production of different types of paper and cardboard [10], but process water cannot be recycled easily because dissolved and colloidal substances (DCS) and electrolytes become enriched with water recycling. This has the effect of adversely affecting paper machine operability and paper quality. In general, the DCS in process water comes from fibre extractives and the chemical additives consumed during manufacturing and they can also react with electrolytes $\mathrm{Ca}^{2+}$ and $\mathrm{Mg}^{2+}[11,12,13,14]$.

The degree to which these impurities need to be removed before reuse of the water is not well known. However, the higher the quality of the paper produced, the cleaner the water used in manufacturing should be $[15,16]$. Recently, membrane separation technology has attracted more and more attention as an alternative way to treat paper mill wastewater. Some nanofiltration (NF), ultrafiltration (UF) and reverse osmosis (RO) membrane filtration plants have been installed in pulp and paper mills to purify secondary and tertiary effluents using external biological treatment. The major advantage of the membrane separation technology is that it can save energy, reduce the carbon footprint and simplify operation. Many reports have demonstrated the applicability of membrane technology to pulp and paper mill wastewater [17]. Ultrafiltration can be used as an advanced tertiary treatment to remove suspended solids and DCS during the treatment of paper industry effluent. This allows the re-utilisation of process water and reduces fresh water consumption. However, membrane fouling limits the application and use of UF and, currently, this treatment technology can only be used to filter paper mill effluent that has been pre-treated and meets discharge standards [18].

DCS might play a number of different roles in membrane fouling. Colloidal substances larger than the pores cannot pass through the membrane and they will be deposited on the membrane surface blocking the pores. Dissolved substances that are smaller than the membrane pore-size are adsorbed within the pores and/or deposited within the membrane, shrinking the pore 
diameter and increasing membrane resistance. In addition, once pores are blocked, other DCS can form a cake on top of the membrane, adding additional resistance via another porous layer covering the membrane $[19,20]$.

According to research performed by Chen et al. [21], reversible membrane fouling during ultrafiltration accounted for $85.52 \%$ of total fouling. It primarily originated from retention aids, drainage aids, polyacrylamide and wet strength resins. While irreversible adsorptive fouling accounted for $14.48 \%$ and mostly came from sizing agents, coating chemicals (oxidants for polyester or resin and polyester or resin surface sizing agents) and other sources. Moreover, the presence of dissolved multivalent metal ions, especially $\mathrm{Ca}^{2+}$, accelerated membrane fouling [22]. Some research aimed at reducing biofilm formation has demonstrated that bacterial cells (Pseudomonas fluorescens) on cellulose fibres can affect retention [23]. Pratima Bajpai [24] studied the types of microorganisms encountered in the papermaking process that can contribute to fouling. It was found they include aerobic spore-forming bacteria (Bacillus), aerobic non-sporulating bacteria (e.g. Acinetobacter and Alcaligenes) and anaerobic bacteria (e.g. Desulfovibrio).

The empirical and theoretical mathematical models used to describe permeate flux decline over time for a UF process and to describe membrane fouling mechanisms can be found in the literature. Some of the most well known are described by Hermia [25], Song [26], Ho and Zydney [27], Bhattacharjee and Datta [28] and Lin et al. [29]. In general, empirical models are very accurate because they describe experimental results by fitting a mathematical equation to the data obtained without considering any theoretical parameters. Despite this, they cannot explain the fouling mechanisms involved in membrane filtration. On the other hand, theoretical models can help in the understanding of fouling phenomena, although they are less accurate if experimental data are not used to estimate some of their parameters [30].

The importance and the novelty of the current work comes from the need to advance understanding of the behaviour of the UF process and its application for the removal of colloidal organic matter from treated wastewater (effluent arising from the secondary biological reactor) in paper mills. Focused especially on the effects of dissolved and colloidal substances on membrane fouling mechanisms. The study also included the analysis of a dynamic model for permeate flux decline and resistance due to membrane fouling (fouling resistance). The mathematical modelling used to verify the experimental results was based on a pore blocking model for tangential filtration adapted from Hermia's dead-end filtration laws [25, 31] and the resistance-in-series model at constant pressure [26]. 


\section{Materials and methods}

\subsection{Treated wastewater used in the ultrafiltration process}

The wastewater samples used in this study came from a secondary clarifier effluent from a wastewater treatment plant (WWTP) in a papermaking factory located in the south of the Valencian autonomous region in Spain. The characteristics of the treated wastewater used to foul the membrane are given in Table 2 .

\subsubsection{Analytical procedure}

The turbidity was measured using a Dinko 112 turbidimeter (ASTM D1889). COD and DOC were measured using a Merck Picco photometer at the wavelengths of $605 \mathrm{~nm}$ (D1252 - 06 ASTM and D7573 - 09 ASTM). The total nitrogen in the effluent was analysed using a Merck photometer and a Merck TR-300 thermoreactor (ASTM D8083). Sediment solids and total suspended solids analyses were carried out according to the Standard Methods [32]. The sample particle size distribution was measured using the dynamic light-scattering method in a Zetasizer Nano ZS instrument (Malvern Instruments). Conductivities were measured using a WTW level 3 conductivity device (ASTM D1125 - 14). The $\mathrm{pH}$ and temperature were monitored with a BASIC 20 pH-Meter (Crison).

\subsubsection{Pre-treatment before the UF processes}

Before the treated wastewater samples were placed in the ultrafiltration pilot plant they were treated in a conventional filtration plant with a Cintropur® NW 50 filter element and centrifugal propeller and filter cloths with porosities of 50, 25 and 5 microns $(\mu \mathrm{m})$ sequentially. The aim of this pre-treatment was to remove the large suspended solids in the treated wastewater by filtration in order to prevent early membrane pore blocking.

\subsection{Equipment (UF pilot plant)}

Experimental tests were performed in a UF pilot plant, consisting of tanks for feeding and cleaning solutions with a capacity of 10 litres each. The conventionally pre-treated water from the feed tank was pumped to a flat-sheet membrane module (allowing working with two membranes) with $154.8 \mathrm{~cm}^{2}$ effective area for each one. These elements worked in parallel and were operated under cross-flow filtration using a 3CP-1221 piston pump. The required crossflow rates and transmembrane pressures were attained by controlling the input electromotor power and backpressure valve after the membrane module. A cooling/heating 
system was employed to achieve the required temperature. In addition, the plant had data acquisition (temperature, module input and output pressure) through LabVIEW System Design Software. The real-time membrane flux was calculated from the difference between the two weight measures for each permeate, registered on two precision balances using MALTAB ${ }^{\circledR}$ (Mathworks). The schematic diagram for the pilot plant process is shown in Figure 1.

\subsection{UF Membranes}

The UF membranes tested in this study were from Synder Filtration ${ }^{\mathrm{TM}}$ (Vacaville, CA-USA). They were polyethersulfone (PES) flat sheet membranes with a $10 \mathrm{kDa}$ molecular weight cutoff (MWCO). Table 3, shows the characteristics and operating conditions of the membranes used.

\subsection{Filtration experiments and procedures}

\subsubsection{Membrane characterisation}

The water permeability of the membranes was measured without fouling at the beginning of the experiment, with the aim of characterising the 10-kDa MWCO PES membranes. Distilled water was used as the feed solution and measurements were performed under different transmembrane pressures (TMPs) $(1.0,1.5,2.0$ and 3.0 bar) and crossflow rates $(4.5,3.0$ and $1.5 \mathrm{~L} / \mathrm{min}$ ) at $22{ }^{\circ} \mathrm{C}$. Before each test the membrane was worked under compaction conditions at 5 bar for 1 hour. The characterisation process was undertaken for an operation time of 2 hours, it was necessary to stabilise the flux through the membrane during this time.

\subsubsection{Flux decline in UF}

Once the membrane was characterised, the fouling tests were carried out under tangential flow ultrafiltration. The aim of the tests was to determine the ultrafiltration process efficiency under different operational parameters. The experiments were performed at different TMPs (1-3 bar) and crossflow rates $(1.5-4.5 \mathrm{~L} / \mathrm{min})$, at a constant temperature $\left(22{ }^{\circ} \mathrm{C}\right)$, all the experiments were performed over 2 hours. Permeate flux was calculated from mass data and volume change data, where the permeate density was considered to be the water density at the operating temperature. To keep the feed concentration constant both the permeate and the retained streams were continuously recirculated to the feed tank. 
To identify the fouling mechanism, the membrane was contaminated using a sample of an effluent previously treated by conventional filtration (Section 2.1.2), with the following parameters: TSS $0.012 \mathrm{~g} / \mathrm{L}$, turbidity $39.5 \mathrm{NTU}$, COD $252 \mathrm{mg} / \mathrm{L}$, DOC $130 \mathrm{mg} / \mathrm{L}$ and particle size distribution $158.9 \mathrm{~nm}-1642 \mathrm{~nm}$.

The tests were undertaken for a number of TMPs (1.0, 2.0 and 3.0 bar) at a constant crossflow rate $(4.5 \mathrm{~L} / \mathrm{min})$ and temperature $\left(22^{\circ} \mathrm{C}\right)$. Membrane fouling was analysed in two stages. The first was based on the pore blocking model (Section 3.1), which is responsible for the initial permeate flux decline, and the second was based on the modelling of cake formation (Section 3.2), which is the cause of long-term gradual flux decline. The data predicted by the model were compared with the experimental results obtained in the membrane fouling experiments as shown in Results and Discussion.

\subsection{Cleaning procedures}

Membrane cleaning is necessary to restore the permeate flux through the membrane. It can be achieved by hydraulic, mechanical or chemical methods and techniques which depend on factors such as foulant characteristics, membrane material, and membrane configuration [33, 34].

The study of permeate flux recovery after membrane cleaning was carried out on a $10 \mathrm{kDa}$ MWCO PES membrane with an initial water permeate flux $\left(\mathrm{J}_{0}\right)$ of $68.6\left(\mathrm{~L} / \mathrm{m}^{2} / \mathrm{h}\right)$, which had been fouled by the recycled paper wastewater. The membrane cleaning procedure was undertaken using two methods (chemical cleaning and hydraulic cleaning) with the aim of evaluating the cleaning efficiency $\left(\mathrm{C}_{\mathrm{E}}\right)$.

Chemical cleaning was carried out using the following procedure:

- Rinsing with deionised water (10 min);

- Cleaning with aqueous 1.0 M NaOH solution, in deionised water (30 min) at pH 8.5;

- Rinsing with deionised water (10 min).

Operating conditions: $\mathrm{T}=25^{\circ} \mathrm{C}, \mathrm{P}_{\mathrm{in}}=4.5$ bar and crossflow rate $=4.5 \mathrm{l} / \mathrm{min}$ (for each cleaning step). The hydraulic cleaning was carried out using only one simple step using deionised water for 20 minutes, at a temperature of $25^{\circ} \mathrm{C}$ and transmembrane pressure of $4.5 \mathrm{bar}$.

Further description of the rinsing / cleaning protocols can be found in P. Blanpain et al. [35] and M. Rabiller-Baudry et al. [36].

Permeate flux recovery (FR) by chemical and hydraulic cleaning was calculated as follows Eq.1: 


$$
F R(\%)=\frac{J_{p}(t)}{J_{0}} .100
$$

The effectiveness of chemical and hydraulic cleaning was evaluated using the cleaning efficiency [37], calculated according to Eq. 2:

$$
C_{E}(\%)=\frac{R_{t}-R_{\text {res }}}{R_{t}} .100
$$

\section{Model Description}

\subsection{Fouling models for cross-flow filtration}

The pore blocking mechanism models developed by Hermia [25] for constant pressure filtration based on dead-end filtration correspond to four basic types of fouling: complete blocking, intermediate blocking, standard blocking and cake layer formation. The characteristic form of the Hermia model is given in Eq. 3 .

$$
\frac{d^{2} t}{d V^{2}}=k\left(\frac{d t}{d V}\right)^{n}
$$

Where, $t$ and $V$ are the filtration time and cumulative permeate volume, respectively, and $k$ and $n$ are two model parameters. The constant $\mathrm{k}$ is the resistance coefficient depending on the suspension properties and operating conditions, in addition to other parameters. The constant $n$ is a dimensionless number that is related to the fouling mechanism, with 2.0 used for complete blocking, 1.5 for standard blocking, 1.0 for intermediate blocking, and 0 for cake filtration. Figure 2 shows the fouling mechanisms considered by the four basic types of fouling blocking laws.

Hermia's pore blocking models adapted to crossflow ultrafiltration are the most useful and applicable when modelling to predict permeate flux decline in the membrane process [38, 39]. The general form of the equation for the four fouling mechanisms in cross-flow filtration is shown in the following equation.

$$
-\frac{d J}{d t}=k\left(J-J_{s s}\right) \cdot J^{2-n}
$$

The equations relating the permeate flux to filtration time for the individual models are given below, where $J_{0}$ is the initial permeate flux calculated at time $\mathrm{t}=0$. 
3.1.1 Complete blocking model for crossflow filtration $(\mathrm{n}=2)$

In the complete blocking model, it is assumed that each particle blocks an open pore completely, as shown in Figure 3 (a). This type of fouling occurs when the size of the solute molecules is greater than the size of the membrane pores. Therefore, pore blocking takes place on the membrane surface and not inside the membrane pores. The permeate flux can be simply represented by Eq. 5 [25, 34].

$$
J_{p}=J_{s s}+\left(J_{0}-J_{s S}\right) \cdot e^{-K_{C} \cdot t}
$$

\subsubsection{Intermediate blocking model for crossflow filtration $(\mathrm{n}=1)$}

This model assumes that the rate of pore blocking is proportional to the number of open membrane pores. Intermediate blocking occurs when the solute molecule size is similar to the membrane pore size (Figure 3 (b)). Thus, some molecules can obstruct a membrane pore entrance without blocking the pore completely [31]. The relationship between the permeate flux and the filtration time can be obtained by Eq. $6[31,34]$.

$$
J_{p}=\frac{J_{0} \cdot J_{s s} \cdot e^{K_{i} \cdot J_{s s} \cdot t}}{J_{s s}+J_{0}\left(e^{K_{i} \cdot J_{s s} \cdot t}-1\right)}
$$

\subsubsection{Standard blocking model for crossflow filtration $(n=3 / 2)$}

The standard pore-blocking model considers that particles enter the membrane pores and become deposited over the pore walls, as the particle diameter is considerably smaller than the pore size [31], as shown in Figure 3 (c). Thus, the pore volume decreases proportionally to the filtrate volume per unit membrane area, consequently the filtrate rate under constant pressure conditions decreases with decreasing pore size, as described in Eq. 7 [25, 33].

$$
J_{p}=\frac{J_{0}}{\left(1+J_{0}^{1 / 2} \cdot K_{s} \cdot t\right)^{2}}
$$

\subsubsection{Cake formation model for crossflow filtration $(\mathrm{n}=0)$}

In the cake formation model, each solute molecule locates on others that have already arrived and that are already blocking some pores as there is no room to directly obstruct any membrane area [34, 39], as shown in Figure 3 (d). The solute molecules do not enter the membrane pores; they form a gel layer over the membrane surface [34]. The filter cake consisting of the particles deposited on the membrane surface gradually grows as filtration continues, and the relationship between flux and time can be written as Eq. $8[34,38]$.

$$
J_{s S}^{2} \cdot K_{g l} \cdot t=\ln \left[\left(\frac{J_{p}}{J_{0}} \cdot \frac{J_{0}-J_{s s}}{J_{p}-J_{s S}}\right)\right]-J_{s s}\left(\frac{1}{J_{p}}-\frac{1}{J_{0}}\right)
$$




\subsection{Constant-pressure filtration and cake formation}

Darcy's law is used to describe the relationship between flux, pressure and resistance in the membrane separation process. The resistance-in-series model is based on the fact that flux decline is comprised of different factors, including pore adsorption, pore blocking, cake formation, and concentration polarisation [40]. In this model, permeate flux through a membrane is proportional to the applied pressure and inversely proportional to the resistance caused by the cake layer and the membrane and governed by the general filtration equation (Darcy's law) given as:

$$
J_{p}=\frac{\Delta P-\Delta P_{c}}{\mu \cdot\left[R_{m}+R_{c}(t)\right]}
$$

The hydraulic resistance due to the cake formation $R_{c}$ can be considered as the sum of three deferent factors: $R_{p l}$, the polarisation layer resistance; $R_{a d}$, the fouling resistance caused by particle adsorption; and $R_{f}$, the fouling resistance, which can be divided into irreversible and reversible.

After the membrane pores have become blocked, further deposition of particles on the membrane surface will form a cake layer. Cake formation creates an additional resistance layer to the permeate flow [8]. The deposition of the solute molecules (particles) on the membrane surface can be calculated using a mass balance:

$$
\delta(t)=\frac{1}{C_{g}} \int_{0}^{t} J_{p} \cdot C_{0} \cdot d t
$$

Substituting mass balance Eq. 10 into Darcy Law Eq. 9 to calculate the permeate flux, using resistance-in-series with the membrane's hydraulic resistance $\left(R_{m}\right)$ and the hydraulic resistance of the cake formation $\left(R_{c}\right)$, rearranging we have:

$$
J_{p}(t)=\frac{\Delta P-\Delta P_{c}}{R_{b m}+r_{c} \cdot \delta(t)}
$$

The cake resistance $R_{C}$ is assumed to be proportional to cake thickness:

$$
R_{c}=r_{c} . \delta(t)
$$

$r_{c}$ is the specific cake resistance per unit cake thickness $\left(\mathrm{m}^{2}\right)$. During constant-pressure filtration, the specific flux declines over time due to the increasing cake resistance.

Filtration models often use the well-known Kozeny-Carman relationship to calculate the specific resistance of a cake with a constant concentration. These models are mostly used when colloids are being filtered [41]. To estimate the specific resistance of the fouling layer, Eq. 13 was considered, the simple Carman-Kozeny equation [26, 42, 43]. 


$$
r_{c}=\frac{K \cdot \mu \cdot(1-\varepsilon)^{2}}{d_{p}^{2} \cdot \varepsilon^{3}}
$$

where $K$ is the Carmen-Kozeny constant, $\varepsilon$ is the porosity and $d_{p}$ is the particle diameter.

The critical pressure, independent of the applied pressure and permeate flux, is determined by the thermodynamic properties of the suspensions [44] and it is given by Eq. 14:

$$
\Delta P_{c}=\frac{3 k_{m} T}{4 \pi d_{p}^{3}} N_{F c}
$$

With an estimate of specific cake resistance $\left(r_{c}\right)$ and substituting Eq. 10 into Eq. 11, rearranging the terms results in:

$$
\left(R_{b m}+r_{c} \cdot \frac{C_{0}}{C_{g}} \int_{0}^{t} J_{p} \cdot d t\right) \cdot J_{p}=\Delta P-\Delta P_{c}
$$

Eq. 13 can be integrated and solved for $J_{p}$ to give an expression to predict the flux decline and the growth in cake layer as a function of time (t). The solution of Eq. 16 is:

$$
J_{p}(t)=\frac{\left(\Delta P-\Delta P_{c}\right)}{R_{b m}}\left(1+\frac{2 r_{c}\left(\Delta P-\Delta P_{c}\right)}{R_{b m}{ }^{2}} \frac{C_{0}}{C_{g}} t\right)^{-1 / 2}
$$

Combining Eq. 9 and Eq. 16 we can calculate the resistance of the cake layer to the permeate flow over time.

$$
R_{c}(t)=R_{b m}\left[\left(1+\frac{2 r_{c}\left(\Delta P-\Delta P_{c}\right)}{R_{b m}{ }^{2}} \frac{C_{0}}{C_{g}} t\right)^{1 / 2}-1\right]
$$

And the cake thickness on the membrane over time is then given by:

$$
\delta(t)=\frac{R_{b m}}{r_{c}}\left[\left(1+\frac{2 r_{c}\left(\Delta P-\Delta P_{c}\right)}{R_{b m}{ }^{2}} \frac{C_{0}}{C_{g}} t\right)^{-1 / 2}-1\right]
$$

\section{Results and discussion}

\subsection{Membrane characterisation}

The experimental data for the pure water permeate flux through the membrane (Figure 1) were used to evaluate the membrane hydraulic resistance $\left(R_{m}\right)$ according to Darcy's law:

$$
J_{p}=\frac{\Delta P}{\mu \cdot R_{m}}
$$

The values obtained for membrane resistance as a function of the applied transmembrane pressure are shown in Figure 3. 


\subsection{Physical and chemical aspects of treated wastewater after the ultrafiltration process}

It is interesting to observe the performance of the separation by ultrafiltration from a physical and chemical point of view before evaluating the modelling of membrane fouling and pore blocking mechanisms. The results obtained for the physical-chemical parameters are given in Table 4.

Ultrafiltration removed 54.36\% of COD from the treated wastewater (effluent from WWTP) as compared to that of the secondary biological reactor, indicating that a considerable portion of the organic matter is colloidal. Removal of nitrogen could be observed, with a reduction from $1.7 \mathrm{mg} / \mathrm{L}$ to $1.1 \mathrm{mg} / \mathrm{L}$ (64\% removal). Suspended solids were almost completely removed by the conventional filtration (filter with a pore size of $5 \mathrm{~mm}$ ) and UF, with a total decrease of $99 \%$. The turbidity was reduced by $99.5 \%$ after ultrafiltration treatment and the particle size distribution in the secondary biological reactor effluent greatly decreased from the range 188.7 - $5499.03 \mathrm{~nm}$ to 99.10 - $334.2 \mathrm{~nm}$ following UF. Both parameters demonstrated the effective removal of macromolecular colloids from recycled paper and cardboard process water. The concentration of dissolved organic carbon before and after ultrafiltration is practically the same, less than $15 \%$ was removed by UF, results that were expected. Conductivity was around 3.06 $\mathrm{mS} / \mathrm{cm}$ after UF treatment, a less than $14 \%$ decrease; a possible explanation for this effect may be that the UF process cannot remove electrolyte complexes of the dissolved and colloidal substances.

\subsection{Pore Blocking Mechanism}

Parameter $k$ was estimated and fitted to the four blocking models according to the nonlinear regression optimisation procedure, using MATLAB $^{\circledR}$ software. The predictions for the nonlinear regression fitted for each pore blocking model were compared to the experimental ultrafiltration data. The following three figures (Figs. 4, 5 and 6) present the fitting of the experimental ultrafiltration data to the Hermia blocking model, at the pressures indicated above. The predictive accuracy of the model was examined using the sum of the squares for the residual coefficients of determination $\mathrm{R}^{2}$, between the numerical predictions and experimental data shown in the Table 5.

Note that the $\mathrm{R}^{2}$ values for each fit of the pore-blocking model vary depending on the operating conditions used (transmembrane pressure). Table 5 shows that at 3 bar (TMP) the best fitting model, and thus the highest $\mathrm{R}^{2}$ value, was for the intermediate blocking model with an average $\mathrm{R}^{2}$ value of 0.9671 . At 2 bar, a good fit was noted for the approximation between complete 
blocking $\left(\mathrm{R}^{2}=0.9725\right)$ and intermediate blocking $\left(\mathrm{R}^{2}=0.9632\right)$. The differences between the experimental data and the fitted model are the highest for a low transmembrane pressure (1 bar), as observed in Figure 6 and Table 5. It is important to note that the membrane does not have a homogeneous pore size distribution, thus fouling does not occur in the same way and at the same rate at every pore.

From Figures. 4, 5 and 6 and Table 5 it can be concluded that for all cases the best fit to the experimental data corresponds to the intermediate and complete blocking model followed by the gel layer formation model. However, standard pore-blocking may also occur within the membrane. In addition, the materials accumulated on a membrane surface that cannot be removed by cleaning procedures (backwash) and/or cross-flow can lead to irreversible fouling, resulting in permanent permeability loss and membrane fouling [45]. Figure 7 shows the normalised flux decline and filtration cycles under reversible and irreversible membrane fouling (normalised flux partial recovery), for a $10 \mathrm{kDa}$ PES membrane under operating conditions of $22{ }^{\circ} \mathrm{C}, 3.0$ bar and $4.5 \mathrm{l} / \mathrm{min}$.

Through the pore blocking models analysis it is also possible to suggest that the colloidal matter is the main cause of the fouling as it forms a cake on the membrane. This is related to the permeability of the cake structure and gel layer formed by large colloids (i.e. $>220 \mathrm{~nm}$ ). In addition, dissolved substances are causing fouling by precipitating on the membrane surface and becoming adsorbed within the membrane pore space (dissolved material $<220 \mathrm{~nm}$ ). It is worth mentioning that the particle size distribution in the feed stream after the conventional filtration was between 1642 - $158.9 \mathrm{~nm}$, which suggests the presence of both dissolved and colloidal matter.

The composition of DCS is very complex, most of this is organic matter, which comes from soluble carbohydrates, macromolecule such as lignin, anionic polymers, heteropolysaccharides such as hemicelluloses, lipophilic extracts of wood and papermaking additives [46]. It is important to mention that in this study measures were not taken to characterise the foulant components responsible for membrane fouling, which will be undertaken in future work.

\subsection{Modelling of membrane fouling (constant-pressure filtration)}

It has previously been shown that in an ultrafiltration process under constant pressure, the permeate flux declines as the resistance to the filtration increases, as the membrane pores become blocked during cake formation by retained particles (suspended solids, colloids and dissolved substances). Furthermore, immediately after pore blockage, the permeate flux still declines due to the formation and growth of a cake layer on the membrane surface (cake 
filtration). A cake layer forms on the membrane surface as the growth of the retained particles increases adding to the cake layer thickness $[26,47]$. The main reference for the mathematical model used in this article to predict permeate flux decline due to membrane fouling in an ultrafiltration process is the model proposed by Song [26, 48]. Figure 8 shows the flux decline for experimental ultrafiltration data and theoretical modelling.

During the modelling analysis of the permeate flux decline (membrane fouling), two stages of ultrafiltration were observed. The first stage corresponds to the blocking of the pores themselves, during which the permeate flux decreases quickly, to a negligible amount. It can be seen that the model fits the data well until about 16 minutes, when the transition to the second stage, cake layer filtration, takes place. This is the predominant filtration mechanism from around minute 50. The permeate flux decreases from an initial value of $1.82 \times 10^{-5} \mathrm{~m} / \mathrm{s}$, corresponding to the permeability without fouling, to $7.44 \times 10^{-6} \mathrm{~m} / \mathrm{s}$ after 8 hours operation.

However, the overall system permeability reduces during both pore blocking stages. Thus, during the initial blocking period, the reduction in membrane permeability must be due to the progressive plugging of the membrane, until the cake filtration period starts. From this time on, the reduction in membrane permeability is caused by the formation of a cake structure and gel layer.

In the proposed model the specific cake resistance per unit cake thickness was $r_{c}=$ 3.008.10 $12\left(\mathrm{~m}^{-2}\right)$ which can be approximately related to the properties for spherical particles given by the Carman-Kozeny relationship in Equation 13 [26, 42, 43]. Based on previous studies and empirical observations of granular media filtration of rigid spherical particles [49, 50], the model assumed a Kozeny constant of around $4.9<\mathrm{K} 7.1$ and a constant porosity of around 0.36. A particle volume fraction of 0.64 was assumed for the specific resistance of cake structures with a constant concentration, however, in reality, for colloidal and dissolved substances the particles are most commonly polydisperse and compressible, therefore, the porosity within the cake layer and the cake permeability should vary temporally. For lowpressure membrane operations (experimental data 3 bar), it was assumed the filtration number and porosity of the retained particles corresponds to $\mathrm{Nf}>15$ (packing porosity of about 0.36 ) for the idealised situation of monodisperse suspensions of rigid spheres [21, 26, 27]. Figure 9 show the resistance of the cake layer $\left(\mathrm{m}^{-1}\right)$ and cake thickness from Eq. 16 as a function of UF time (8 hours).

According to research performed by Chen et al. [11] and Puro et al. [22], the foulants on the membrane surface and within pores arise from DCS, especially fatty acids, resin acids, lignins and some traces of sterols, steryl esters and triglycerides. Moreover, the presence of dissolved 
multivalent metal ions, especially $\mathrm{Ca}^{2+}$, accelerated membrane fouling [18, 22]. Although the approach of this work has been to demonstrate and model the membrane fouling mechanism, the main objective of the follow-on research will be the characterisation of the foulants and the identification of the specific chemical components on the surface and within the membrane. This will be undertaken using techniques such as scanning electron microscope (SEM), Fourier transform infrared (FTIR) spectroscopy and gas chromatography-mass spectrometry (GC-MS) $[11,18,22]$.

\section{Conclusion}

In this work, ultrafiltration was used to remove dissolved and colloidal substances remaining in the effluent from a papermaking factory wastewater treatment plant. The results show that these substances cause a significant permeate flux decline resulting from membrane fouling.

From the modified Hermia's models studied in this work it is clear that intermediate and complete blocking can explain the experimental results obtained for all the experimental conditions with a high goodness of fit $\left(\mathrm{R}^{2}>0.96\right)$.

The best conditions for UF providing the highest flux were found at TMP $=3$ bar and a crossflow rate of $4.5 \mathrm{~L} / \mathrm{min}$ at $22{ }^{\circ} \mathrm{C} \pm 0.5{ }^{\circ} \mathrm{C}$. The particle size distribution was greatly decreased from the range of $5499.1-188.7 \mathrm{~nm}$ to $334.2-99.1 \mathrm{~nm}$. As a consequence, the turbidity was reduced by $99 \%$, and the organic colloidal matter was effectively eliminated, considering that its average size is greater than $220 \mathrm{~nm}$. In addition, as COD was removed by $54 \%$ down to $110 \mathrm{mg} / \mathrm{L}$ it could be concluded that ultrafiltration is suitable for producing water that can be reused in different papermaking processes.

Modelling of the membrane processes is of interest since it aids the selection of a suitable TMP and crossflow rate. This is positive from an operational point of view because, by manipulating the operating conditions, it is possible to obtain better control of the membrane fouling processes. 


\section{LIST OF FIGURES:}

Figure 1. Schematic diagram for the ultrafiltration membrane process.

Figure 2. Schematic illustration of the four filtration blocking fouling mechanisms: (a) complete blocking model, (b) intermediate blocking model, (c) standard blocking model and (d) cake filtration model.

Figure 3. Pure water permeate flux vs. applied pressure. TMPs (1.0, 1.5, 2.0 and 3.0 bar) at 22 ${ }^{\circ} \mathrm{C}$, crossflow rate of $4.5 \mathrm{~L} / \mathrm{min}$ and operation time 2 hours. The value obtained for the intrinsic membrane resistance $\left(\mathrm{R}_{\mathrm{m}}\right)$ for the flat sheet $10 \mathrm{kDa}$ PES membrane was $1.629 \times 10^{12}\left(\mathrm{~m}^{-1}\right)$.

Figure 4. Hermia's pore blocking models fitting for recycled paper wastewater $10 \mathrm{kDa}$ PES membrane filtration experiments, at 3 bar.

Figure 5. Hermia's pore blocking models fitting for recycled paper wastewater $10 \mathrm{kDa}$ PES membrane filtration experiments, at 2 bar.

Figure 6. Hermia's pore blocking models fitting for recycled paper wastewater $10 \mathrm{kDa}$ PES membrane filtration experiments, at 1 bar.

Figure 7. Normalised flux recovery under reversible and irreversible membrane fouling. Resistance by total fouling $2.39 \times 10^{13} \mathrm{~m}^{-1}$

Figure 8. Comparison between experimental flux decline and theoretical model for permeate flux with cross flow for a flat-sheet $10 \mathrm{kDa}$ PES membrane in cross flow filtration mode as calculated from Eq. 14 (conditions: $\mathrm{TMP}=3.0 \mathrm{bar}, \mathrm{Cg}=0.7, \varepsilon=0.3, \mathrm{C}_{0}=0.2 \mathrm{~g} / \mathrm{L}, \mathrm{a}_{\mathrm{p}}=158 \mathrm{~nm}$, $\left.\mathrm{Rm}=1.65 \times 10^{13} \mathrm{~m}^{-1}\right)$.

Figure 9. Resistance of the cake layer (Eq. 15) and cake thickness (Eq. 16) as a function of UF time ( 8 hours) in flat-sheet, crossflow filtration at constant pressure.

Conditions: TMP $=3.0$ bar, $\mathrm{C}_{\mathrm{g}}=0.7, \varepsilon=0.3, \mathrm{C}_{0}=0.2 \mathrm{~g} / \mathrm{L}, \mathrm{a}_{\mathrm{p}}=158 \mathrm{~nm}, \mathrm{R}_{\mathrm{m}}=1.65 \times 10^{13} \mathrm{~m}^{-1}$, $r_{c}=3.01 \times 10^{12}\left(\mathrm{~m}^{-2}\right)$. 
